\title{
GOETHE Y KANT: ARTE, NATURALEZA, CIENCIA
}

\author{
Salvador MAS \\ UNED
}

En conversación con Eckermann del 11 de abril de 1827 Goethe afirma que él, por su propia naturaleza, ha recorrido un camino similar al de Kant. Aunque escribió su Metamorphose der Pflanzen antes de saber nada del filósofo, esta obra «ist ganz im Sinne seiner Lehre». Goethe se siente «kantiano» en un sentido peculiar; no afirma seguir o aceptar las tesis de Kant, entiende que sus investigaciones botánicas tienen un sentido kantiano. ¿Cuál? ¿Qué sentido ve Goethe en la obra de Kant? El pronunciamiento más claro a este respecto puede leerse en el ensayo Einwirkung der neueren Philosophie ${ }^{1}$, donde el poeta manifiesta su admiración por la Kritik der Urteilskraft, porque en esta obra veía enlazadas sus preocupaciones más dispares: de acuerdo con Goethe, Kant trata de la misma manera las producciones del arte y las de la naturaleza: "El discernimiento estético y el teleológico se iluminan recíprocamente» ${ }^{2}$. La Critica del discernimiento le interesa porque considera que expresa "la vida interna tanto del arte como de la naturaleza" o lo que es lo mismo, la insuficiencia de los modelos explicativos mecanicistas.

Es cierto que Kant, por ejemplo en el $\$ 75$ de la tercera crítica, escribe: «ni por asomo podemos llegar a conocer suficientemente los seres organizados ni su posibilidad interna según principios meramente mecánicos de la naturaleza, ni mucho menos acertar a explicárnoslos" (B 338), pero no lo es menos -asi se titu-

${ }^{1}$ M.A. 12, 94-97. En la medida de lo posible cito las obras de Goethe por la "Münchner Ausgabe" (M.A.): Johann Wofgang Goethe. Sämtliche Werke nach Epochen seines Schaffens. 21 Bde. Herausgegeben von Karl Richter in Zusammenarbeit mit Herbert G. Göpfert, Norbert Miller und Gerhard Sauder. München/Wien: Carl Hanser Verlag. Indico siempre la obra citada remitiendo al volumen y al número de página de la M.A. Cuando ello no ha sido posible indico en nota a pie de página la edición utilizada.

${ }^{2}$ M.A. $12,96$. 
la este parágrafo- que «el concepto de una finalidad objetiva de la naturaleza es un principio crítico de la razón para el discernimiento reflexionanten; no es que los modelos explicativos mecanicistas sean insuficientes en sí mismos porque la naturaleza, también en sí misma, obre como el artista, sucede que dada la peculiar índole de nuestras capacidades cognoscitivas tenemos que aceptar una causa suprema que obre intencionalmente, esto es, de manera no mecánica. A Goethe no le preocupaban estas sutilezas, y es muy probable que de la Crítica del discernimiento le interesara particularmente la crítica a esa concepción vulgar de la teleología que identifica finalidad con utilidad y de la que Voltaire ya se había mofado en su Cándido ${ }^{3}$. Goethe se sintió atraído por el análisis crítico que Kant había realizado del concepto de finalidad, en él se veía reflejado como artista y como poeta, porque desde la perspectiva goetheana no está en juego la necesidad de pensar la naturaleza como si fuera una obra de arte, sino la unidad incondicionada entre arte y naturaleza que se refleja en la identidad entre el artista y el investigador de la naturaleza. Para Kant la naturaleza es «la existencia de la cosa en tanto que determinada según leyes universales" (das Dasein der Dinge, sofern es nach allgemeinen Gesetzen bestimmt ist $)^{4}$. Goethe, dominado por el espíritu faústico, no puede quedarse con esta determinación unilateral que sólo atiende a la natura naturata. La naturaleza, al igual que el artista, también es creadora.

En la fase Sturm und Drang (en su correspondencia con Behrisch, en el relato del viaje a Suiza de $1775 . .$.$) la naturaleza era para Goethe una totalidad y una$ vivencia: naturaleza que se disfruta, en la que uno querría sumergirse, lugar de recreo y a la vez obstáculo enemigo a superar; también la naturaleza cuya fuerza creadora es semejante a la del genio, la naturaleza en definitiva de ese rousseauniano Werther que se siente cercano a la tierra y sabe próximas al corazón sus innumerables manifestaciones, en especial las más terroríficas y amenazadoras que yacen ocultas en ella. El mismo Goethe parodió este lenguaje en su juvenil drama festivo Satyros oder die vergötterte Waldteufel. Pero la gran transformación se produce a su regreso de Italia: la mirada sobre la naturaleza deja de ser "emotiva» y se convierte en "científica». Goethe no habla de «la naturaleza" sino de los "objetos de la naturaleza" plantas, animales o minerales que ahora no sacuden el ánimo, sino que despiertan un interés por ellos mismos y por sus múltiples interrelaciones. El poeta se considera un "empírico" un

${ }^{3}$ Cfr. E. Cassirer, "Goethe und die kantische Philosophie" [1944], en Rousseau, Kant, Goethe, Hamburg, Felix Meiner, 1991, pp. 67 y ss.

${ }^{4}$ Prolegomena zu einer jeden künftigen Metaphysik $\$ 14$ (Ak. Aus. 4, 294) 
"realista" incluso un Stockrealist ${ }^{5}$, lo cual no quiere decir que haya abandonado la concepción de la naturaleza como totalidad; sucede más bien que esa totalidad se dice ahora de otra manera, como sugiere el título de su trabajo sobre el hueso intermaxilar: "Versuch aus der vergleichende Knochlehre, daß der Zwischenknoch der obern Kinnlade dem Menschen mit dem übrigen Tiere gemein sei» ["Estudio de osteología comparada: que el hueso intermaxilar de la mandíbula superior de los seres humanos es común con los restantes animales»]. Dos ideas son importantes en este nuevo lenguaje, muerto y pétreo para los románticos: la de la unidad e irrepetibilidad de los fenómenos y la de su conexión e interrelación.

En un escrito de 1817, Der Verfasser teilt die Geschichte seiner botanischen Studiums mit $t^{6}$, Goethe reconoce la gran influencia que sobre él ejerció Linné, pero también señala el decisivo punto que le separa del gran botánico sueco: mientras que éste intenta separar y aislar, él, "según las necesidades más íntimas de mi ser" (nach dem innersten Bedürfnis meines Wesens) aspira siempre a la unificación (Vereinigung); también son interesantes a este respecto sus comentarios sobre el Fragments pour un Dictonnaire de termes d'usage en Botanique: frente a esta obra se siente como un "poeta innato" que aspira a conformar sus palabras inmediatamente en los objetos particulares "para así darles satisfacción en alguna medidan; las palabras son como las teselas de un mosaico que se engarzan unas con otras para al final conformar una totalidad que da sentido a cada una de las partes, pues aunque los fenómenos son individuales se insertan en un contexto omniabarcador del que la mirada científica ni puede ni debe prescindir. De aquí la tensión entre la multiplicidad de lo particular (los fenómenos observables sensiblemente con los «sanos sentidos") y la necesidad de ordenar con sentido y de forma abarcadora lo así observado. Los versos iniciales de Die Metamorphose der Pflanzen expresan esta problemática de regusto kantiano:

Te desconcierta, amada, la mezcla infinita de esta multitud de flores en torno al jardín.

Escuchas muchos nombres y siempre suprime con bárbaro sonido el uno al otro. Similares son

${ }^{5}$ Cfr. las cartas a Schiller de Agosto de 1792, 9-Julio-1796, 27-Abril-1798, 28-Abril-1798.

${ }^{6}$ M.A. $18 \cdot 2,438$ ss. 
todas las formas y ninguna a otra se asemeja.

Y así apunta el coro hacia una ley secreta ${ }^{7}$.

¿Cómo decir la similitud y la desemejanza? ¿Cómo fijar lo particular sin traicionar su irrepetibilidad?

En 1789/90 aparece un importante texto científico goetheano, Versuch die Metamorphose der Pflanzen zu erklären ${ }^{8}$, que es una especie de resumen de los estudios botánicos realizados en Italia e inmediatamente después. Goethe ve en las diferentes partes de una planta particular (cotiledón, tallo, nudos, flores y fruto) el resultado de un proceso de transformación surgido en el crecimiento de la planta y en esta medida como modificaciones de una forma única que identifica con la hoja, en cuyo proceso de metamorfosis descubre la legalidad que, según él, obedecen todas las plantas ${ }^{9}$. Este descubrimiento le produjo una enorme satisfacción porque - confiesa a Knebel en carta del 3 de Octubre de 1787 escrita desde Roma - gracias a él ha encontrado una combinación del arte con su concepción de la naturaleza y así uno y otra le resultarán "doblemente queridas"; sigue entonces informando acerca de un clavel muy especial, pues lo que en el norte sólo cabe sospechar, en el sur y bajo la "fisicidad" de su luz, puede verse: «Lo que en el norte sólo sospechaba lo encuentro aquí manifiesto (offenbar) (...) Este verano he encontrado un clavel del cual habían surgido otros cuatro claveles perfectos, y a partir de éstos habrían crecidos otros si la vegetación hubiera tenido suficiente fuerza. Es un fenómeno altamente interesante que transforma mi hipótesis en certeza».

Nada más regresar de Italia Goethe escribió un ensayo sobre «arte, manier y estilo" otro sobre "la metamorfosis de las plantas" y un tercero sobre el "carnaval romano«: los tres en conjunto muestran lo que en aquella época pasaba en su interior (...sie zeigen sämtlich was damals in meinem Innern vorging); entonces,

7 Dich verwirrt, Geliebte, die tausenfältige Mischung

Dieses Blumengewühls über dem Garten umher;

Viele Namen hörest du an, und immer verdränget

Mit barbarischem Klang einer den andern im Ohr.

Alle Gestalten sind ähnlich, und keine gleichet der andern;

Und so deutet das Chor auf ein geheimes Gesetz.

${ }^{8}$ M.A. 3.2, 318.

${ }^{9}$ Cfr. M.L. Kahler, G. Maul, Alle Gestalten sind ähnlich. Goethes Metamorphose der Pflanze, Weimar, Nationale Forschung- und Gedenkstätten der klassischen deutschen Literatur, 1991. 
sin solución de continuidad, se refiere al Versuch die Metamorphose der Pflanzen $z u$ erklären como el intento de "retrotraer los múltiples y particulares fenómenos del señorial jardín cósmico a un único principio universal y simple» ${ }^{10}$ : a propósito de un problema botánico concreto formula la ley que después, a mediados de los 90, expresará de manera general en la Betrachtung über Morphologie überhaupt, esa «teoría de la forma de configuración y reconfiguración de los cuerpos orgánicos" (Lehre von der Gestalt der Bildung und Umbildung der organischen Körper) ${ }^{11}$, cuya tarea es "conocer las configuraciones vivientes como tales, aprehender en su relación sus partes externas visibles, interpretarlas como indicios del interior y así, en la intuición sensible (Anschauung), dominar en cierto modo el Todom. No hace falta señalar, continúa, "lo próximo que está este empeño científico a los impulsos artísticos e imitativos" (Wie nah dieses wissenschaftliche Verlangen mit dem Kunst- und Nachahmungstriebe zusammenhänge... $)^{12}$, pues en uno y otro campo rigen fenómenos primordiales o prototípicos (Urphänomene) que para Goethe no son modelos teóricos, sino realidades observables. Schiller señalaba muy kantianamente que la metamorfosis de las plantas «no era una experiencia, sino una idea" Goethe insiste una y otra vez en que "la ve con los ojos»" ${ }^{13}$.

$\mathrm{Al}$ igual que el poeta o como si fuera un poeta el investigador de la naturaleza ordena las experiencias, da cuenta de ellas y pasa así, en cierto sentido, del lado objetivo al subjetivo ${ }^{14}$. Pero atender al lado subjetivo no implica abandonar la inmediatez sensible de los fenómenos; unir, pues, objetividad y subjetividad, como Goethe creía que hacía en sus investigaciones sobre los colores. En "Bedeutende Förderns durch ein einziges geistreiches Wort" declara que la intención de este escrito es, ciertamente, expresar su concepción de la naturaleza, pero también manifestarse "a sí mismo, mi interior, mi manera de ser». Quizá sea pertinente señalar que este texto, publicado por vez primera en 1823 , pero

10 «Schicksal der Handschrif»" (Zur Morphologie I,I) (M.A. 12, 70).

${ }^{11}$ M.A. 4.2, 201

12 "Die Absicht eingeleitet” (Zur Morphologie I,I) (M.A. 12, 13).

13 "Glückliches Ereignis" (M.A. 12, 88).

${ }^{14}$ En el sentido, por ejemplo, en el que Goethe criticaba el intento de Zelter de determinar las relaciones armónicas mecánicamente, sin atender al músico: “¿Qué es una cuerda y todas sus particiones mecánicas frente al oído del músico? ¿Cómo puede decirse lo que son los fenómenos más elementales de la naturaleza dejando a un lado al ser humano, que debe primeramente domarlos y modificarlos antes de poder asimilarse en alguna medida a ellos?". (Carta a Zelter del 2 deMayo de1808) 
redactado en 1792, lejos de ser una página autobiográfica, se sitúa en el contexto de sus investigaciones morfológicas ${ }^{15}$.

Lejos de alegorías, de las efusiones del corazón del monje enamorado del arte, pero también de todo reduccionismo mecanicista y matematizante, la naturaleza se ve y dice como compendio de todas las cosas que existen y de sus posibles formas fenoménicas en su globalidad. Goethe exige la estricta separación entre física y matemática. Sin embargo, para la ciencia moderna, como bien sabía Kant, la naturaleza es objeto de una experiencia que sólo se alcanza al precio de aislar los fenómenos retrotrayéndolos a un núcleo matemático-formal, pues sólo éste es susceptible de ser expresado mediante leyes universales. Pero esto obliga, a su vez, a olvidar la presencia fáctica y visible en la que se ofrecen las cosas, fuerza a relegar aquello de lo que Goethe en modo alguno quiere prescindir ni en sus investigaciones científicas ni en su labor poética: la inmediatez de lo dado sensiblemente, "inmediatez" tanto de la presencia física como de su recepción por parte de un sujeto.

Esas modulaciones de un enérgico humanismo protestante que son el idealismo y el romanticismo prescinden de la inmediatez de la presencia física de la cosa, quizá porque consideran que el mundo (la naturaleza "bruta" "desnuda" la "pura materia"...) es algo oscuro y terrible donde los seres humanos nunca podrán sentirse acogidos ${ }^{16}$. La ciencia moderna representa la otra cara de la moneda, prescinde del sujeto: la física newtoniana ha separado el experimento de los seres humanos, una gran desgracia (das grösste Unheil der neuern Physik...), pues «el ser humano en sí mismo, en la medida en que se sirve de sus sanos sentidos, es el mayor y más preciso aparato físico que pueda haber» ${ }^{17}$. Hay que emplear «los sanos sentidos" o lo que es lo mismo: "observar fielmente la naturaleza»: "Los observadores fieles de la naturaleza, aunque por lo demás puedan pensar de formas muy diferentes, estarán sin embargo de acuerdo en que todo lo que aparece, todo lo que nos sale al encuentro como fenómeno, tiene que indicar o bien una disociación originaria que es susceptible de unificación, o bien una unidad originaria que puede disociarse (...) Disociar lo unificado, unificar lo disociado: tal es la vida de la naturaleza, el eterno sístole y diástole, la eterna synkrisis y dyakrisis, el inspirar y expirar del mundo en el que vivimos, existimos y somos" ${ }^{18}$.

${ }^{15}$ M.A. 10, 306 ss.

${ }^{16}$ Cfr. T. Eagleton, La idea de cultura, Barcelona, Paidós, 2001, p. 127.

${ }^{17}$ Maximen und Reflexionen [706] (M.A. 17, 846).

${ }^{18}$ Zur Farbenlehre. Didaktische Teil, Nachbarliche Verhältnisse», 739 (M.A. 10, 222). 
Goethe estaba fascinado con los estudios de nubología de Luke Howard ${ }^{19}$. En 1820 publicó el tercer volumen de Zur Naturwissenschaft, donde puede leerse el ensayo "Wolkengestalt nach Howard» ilustrado con algunos dibujos de nubes suyos; Howard fue el primero que "fijó en conceptos las etéreas y siempre cambiantes imágenes de las nubes, que limitó lo indeterminado sin detenerlo y que lo nombró de forma acertada ${ }^{20}$. En el prólogo a este ensayo explica de manera más precisa los motivos de su atracción por el físico y meteréologo inglés: «Abracé la terminología de Howard con alegría, porque me ofrecía un hilo conductor que hasta ese momento echaba de menos (...) Me alegré, pues, de encontrar que una parte integrante de la misma se adecuaba a mi inclinación y forma de vida, y dado que en este Todo infinito todo está en una relación eterna y una cosa produce la otra o se producen recíprocamente, se agudizó mi mirada sobre lo captable por el sentido de la vista. "Realmente, Goethe modifica la terminología de Howard con el fin de poner de relieve que las nubes, de los estratos a los cirros, forman una serie ascendente continua: tras el conjunto de observaciones más o menos empíricas que se leen en la segunda parte de su trabajo se detecta cierta tendencia a interpretar los movimientos de las nubes como un conflicto entre las regiones inferiores y superiores de la atmósfera, donde las nubes, en sus metamorfosis, muestran una irresistible inclinación (o una teleología) a ascender desde las zonas inferiores a las más superiores; a Goethe le interesan las nubes, cierto, pero no como fenómeno atmosférico, sino por la metafórica que ofrecen. ${ }^{21}$

En honor a Luke Howard, Goethe compuso el poema «Howard's Ehrengedächtnis" que comienza con una invocación a la divinidad hindú Camarupa. Goethe toma el nombre del poema épico Megha Duta ( $\mathrm{El}$ mensajero de las nubes") escrito por el poeta Kalidassa, que había podido leer en una versión inglesa. El mismo Goethe afirma que se nombra a esta divinidad en tanto que ser espiritual que modifica las formas según le place y da a las nubes una u otra forma (... die Wolken bildet und umbildet) ${ }^{22}$

${ }^{19}$ Cfr. «Die Ordnung im flüchtigen. Wolkenstudien der Goethezeit», en S. Schulze (Hrsg.), Goethe und die Kunst, Ostfildern, Hatje, 1994.

${ }^{20}$ W.A. II, 12, 234.

${ }^{21}$.Cfr. M.A. 12, 1060 ("Kommentar»). Tb. "Camarupa» (M.A. 11.2, 560).

${ }^{22}$ L.A. 1, 8, 238. 
en el cambio de las formas se complace, quieto, mas luego como sueño desaparece ${ }^{23}$.

Tal es el desafío, fijar aquello por su propia naturaleza absolutamente evanescente; así lo indican los dos primeros versos de la segunda estrofa:

Se excita, pues, ávida la propia imaginación

que lo indeterminado en determinado transforma ${ }^{24}$.

«En la segunda estrofa - se comenta Goethe a sí mismo de nuevo con regusto kantiano- se presenta la función de la imaginación humana (...die Funktion der menschlichen Einbildungskraft), la cual, según un impulso innato, siempre aspira a dar a todo lo azaroso informe alguna conformación necesaria (...welche nach eingebornem Trieb allem ungebildet Zufälligen jederzeit irgendeine notwendige Bildung zu geben trachtet)" 25 . Camarupa, sin embargo, "se dispersa" zerstieben es la palabra que utiliza Goethe, que literalmente significa "deshacerse en polvo" (Der treuste Wolkenbote selbst zerstiebt, "el más fiel mensajero de las nubes en polvo se deshace»). La tercera estrofa celebra poéticamente los méritos de Howard:

Lo que no se puede detener, lo que no cabe alcanzar

él lo aprehendió, él por vez primera lo detiene, determina lo indeterminado y límites le pone ${ }^{26}$.

El poema continúa con una descripción de gran fuerza poética de estratos, cúmulos, cirros y nimbos. Cuando Goethe lo publicó en sus obras completas, dentro del apartado "Gott und Welt» le antepuso otro poema, "Atmosphäre" que cuestiona la posibilidad de llevar a cabo la tarea estructuradora y conformadora cantada en "Howard's Ehrengedächtnis»:

${ }^{23}$ Am Wechsel der Gestalten sich erfreut, Setzt starr sich hält, dann schwindet wie ein Traum

${ }^{24}$ Nun regt sich kühn des eignen Bildens Kraft,

Die Unbestimmtes zu Bestimmten schafft;

${ }^{25}$ L.A. 1, 8, 238.

${ }^{26}$ Was sich nicht halten, nicht erreichen lässt,

Er fasst es an, er hält zuerst es fest;

Bestimmt das Unbestimmte, schränkt es ein. 
El mundo es tan grande y tan ancho,

el cielo tan sublime y vasto:

debo todo ello verlo con los ojos

mas pensarlo bien no se deja ${ }^{27}$.

Cuatro versos "kantianos" que plantean la dificultad de decir científicamente (de forma ordenada, metódica y regulada) lo que sin embargo se ve con toda claridad: en las investigaciones sobre la naturaleza, señala Goethe en el breve ensayo "Bedenken und Ergebung", aparece por un lado la idea, por otro la experiencia y es muy difícil ligar una y otra (...die Schwierigkeit Idee und Erfabrung zu verbinden): la idea es independiente del espacio y del tiempo, la investigación de la naturaleza está limitada a uno y otro, espacio y tiempo están en la idea ligados íntimamente tanto simultánea como sucesivamente, mientras que desde el punto de vista de la experiencia siempre están separados, en la idea se piensan las relaciones causales como sucesivas y simultáneas a un tiempo, lo cual no deja de ser una especie de locura (...und eine Naturwirkung die wir der Idee gemäss als simultan und sukzessiv zugleich denken sollen, scheint uns in eine Art Wahnsinn zu versetzen). No puede suponerse, como se hace en ocasiones, que Goethe no entendiera la «locura» del planteamiento crítico kantiano, porque explica con gran precisión la raíz de la dificultad: “El entendimiento no puede pensar unificado lo que la sensibilidad le transmite de manera separada y así queda por siempre sin solución el conflicto entre lo aprehendido y lo ideado ${ }^{28}$. Enfrentado a problemas semejantes Kant escribió la Crítica de la razón pura, Goethe da palabra a la poesía (... in die Sphäre der Dichtkunst flüchten...). A modo de resumen y culminación de las anteriores dificultades epistemológicas el lector de Zur Morphologie, donde Goethe incluyó el ensayo antes citado, se ve agradablemente sorprendido con el poema «Antepirrhena»:

Mirad así con ojos modestos

la obra maestra de la eterna tejedora,

como en un paso mil hilos teje,

27 Die Welt ist so gross und breit,

Der Himmel auch so hehr und weit

Ich muss das alles mit Augen fassen

Will sich aber nicht recht denken lassen.

28 “Bedenken und Ergebung" (M.A. 12, 99-100). 
mueve la lanzadera arriba y abajo $y$ los hilos fluyen, se encuentran, de un golpe mil tramas teje.

Sin tener nunca que mendigar pues desde siempre lo ha urdido, para que el maestro eterno, consolado, pueda tejer también su urdimbre 29 .

El texto es críptico. Puede pensarse que "el maestro eterno" es el poeta que al igual que la natura naturans, la naturaleza creadora («la eterna tejedora"), teje su tejido, su texto, que representa el mundo ${ }^{30}$. Pero tal texto no es el mundo, sino su metamorfosis poética. Estratos, cúmulos, cirros y nimbos dicen las nubes, pero no son las nubes, no dicen sus metamorfosis. En una anotación de 1823 Goethe reconoce la imperfección de la terminología de Howard: "En la observación de nubes se presentan casos en los que la terminología [de Howard] es insuficienten" ${ }^{31}$, Al igual que el Systema naturae de Linné capta el producto, pero no el proceso de la vida, esta terminología no aprehende la transformación y el instante en el que un estrato asciende para ser entonces cúmulo, momento que el "realista» Goethe quiere decir y que Kant había argumentado que no puede decirse (para nuestras capacidades cognoscitivas).

Goethe reconoce que carece de «órgano" para la filosofía en sentido estricto $^{32}$; sólo después de esta salvedad inicial comenta que al principio no

29 So schauet mit bescheidnem Blick

Der ewigen Weberin Meisterstück,

Wie ein Tritt tausend Fäden regt,

Die Schifflein hinüber herüber schiessen,

Die Fäden sich begegnend fliessen,

Ein Schlag tausend Verbindungen schlägt.

Das hat sie nicht zusammen gebettelt,

Sie hats von Ewigkeit angezettelt;

Damit der ewige Meistermann

Getrost den Einschlag werfen kann.

30 Así lo interpreta B. WITTE, Johann Wofyang Goethe. Gedichte, Stuttgart, Reclam, 2001, p. 1006.

31 W.A. II, 12, 234.

32 Extraña esta afirmación autocrítica porque Goethe sí tenía sentido para «los fantasmas" y como dice Mefistófeles: «Pues allí donde los fantasmas toman sitio /allí también son bienvenidos los filósofos ( (Denn, wo Gespenster Platz genommen, / Ist auch der Philosoph willkommen». Faust II, 7843-44) 
estaba especialmente interesado en la Crítica de la razón pura (...es lag völlig außerhalb meines Kreises). Sin embargo, por imperativo de sus intereses científicos, se vio obligado a enfrentarse con las opiniones de los filósofos, como si fueran objetos (...eben als auch wären Gegenstände). Se dio cuenta entonces de que estaba en juego, una vez más, la antigua cuestión: «... en qué medida nuestro yo y en qué medida el mundo externo contribuyen a la formación de nuestra existencia espiritual». Admite con Kant que aunque todos nuestros conocimientos comienzan con la experiencia, no todos ellos surgen de ella. Sin embargo, el "gran pagano" sólo llegaba hasta donde le interesaba llegar: «... también me dejé seducir por los conocimientos a priori, así como por los juicios sintéticos a priori: pues yo, en toda mi vida, tanto en mis observaciones como en mi labor poética, había procedido sintéticamente y entonces de nuevo analíticamente; la sístole y la diástole del espíritu humano, nunca separadas, siempre ha dejado su pulso en mí, como una segunda respiración". Poco más adelante: "No se me escapa que la naturaleza siempre observa una forma de proceder analítica, un desarrollo a partir de un Todo viviente y pleno de misterio (...eine Entwicklung aus einem lebendigen, geheimnisvollen Ganzen), y entonces parece actuar de nuevo sintéticamente, en la medida en que enlaza en unidad y aproxima mutuamente relaciones en apariencia totalmente extrañas entre sí (...indem ja völlig fremdscheinende Verhältnisse einander angenähert und sie zusammen in eins verknüpft wurden)». Merece la pena detenerse en estos textos que pueden leerse en Einwirkung der neueren Philosophie.

Lo analítico no implica división, es «un desarrollo a partir de un Todo viviente y pleno de misterio». Kant lo refiere a la lógica y al concepto, Goethe a la observación de la naturaleza, a lo que él llama “intuición" (Anschauung), quizá porque como confiesa a Schiller en cąrta del 19 de Febrero de 1802 no puede "comportarse de forma puramente especulativa" sino que necesita buscar "para toda proposición una intuición" (...sondern gleich zu jedem Satze eine Anschauung suchen muss). O lo que es lo mismo, porque no le interesa la investigación (transcendental) de las condiciones de posibilidad del conocimiento, sino la experiencia subjetiva, más exactamente, su experiencia subjetiva en tanto que observador objetivo (que usa "los sanos sentidos») de la objetividad de la naturaleza y ve así, por ejemplo, el instante y el proceso en el que las nubes, desde las zonas inferiores, ascienden hasta las superiores. Desde esta perspectiva es significativa la identificación entre lo "analítico-sintético" y la "sístole-diástole" pues indica que mientras que Kant busca los principios supremos del conocimiento humano, a Goethe (que reconoce que habla de lo que Kant «le ha estimulado, no de lo que ha leído») le 
inquietan los principios conformadores de la naturaleza creadora ${ }^{33}$, porque la naturaleza, al igual que el talento artístico, posee una enorme "fantasía". Ya lo señalaba más arriba, no interesa la necesidad (para nuestras capacidades cognoscitivas) de pensar la naturaleza como si fuera una obra de arte, sino la identidad incondicionada entre el poeta y el investigador de la naturaleza: en conversación con Eckermann del 25 de diciembre de 1825 Goethe considera su fantasía como «una fantasía para la verdad de lo real" (Phantasie für die Wahrheit des Realen).

Se entiende ahora que el poeta investigador de la naturaleza (o el investigador de la naturaleza poeta) considerara deficiente la terminología de Howard; se necesitaria, añade, eine zusammenhängende Beschreibung, una descripción que hiciera justicia al contexto y las conexiones donde las nubes experimentan sus movimientos y metamorfosis; tal descripción en modo alguno puede ser mecánica, sólo puede ser poética. No hay que someter la naturaleza a esquemas matemáticos ni hacerla expresar un sentido místico, religioso o moral, sino simplemente decirla sin más ni más, como hacían los griegos en su arte o en su ciencia y como no. hacen ni el arte romántico ni la ciencia newtoniana que a pesar de tener este rasgo común han tomado direcciones contrapuestas: inequívoco síntoma de la escisión del mundo en el que vivimos. Porque de acuerdo con Goethe arte y ciencia son lo mismo, dos estrategias simbólicas convergentes de decir la naturaleza. Hay que preservar la verdad inmediata de la impresión sensible frente a los ataques de la ciencia y superar así el dualismo anunciado por Kant.

\section{III}

En carta a Knebel del 21 de febrero de 1821 escribe Goethe: "Zur Anschauung gesellt sich die Einbildungskraft». La frase es difícil de traducir: en su forma reflexiva gesellen significa «asociarse» «juntarse» o en sentido temporal "coincidir»; por tanto: la intuición (Anschauung) y la imaginación (Einbildungskraft) van de la mano tanto en sus respectivas funciones como temporalmente: obran lo mismo y al mismo tiempo. La imaginación, continúa, primero copia y repite los objetos (...zuerst nachbildend, die Gegenstände nur wiederholend), pero luego es productiva: anima, desarrolla, amplía y modifica lo captado (...indem sie das Angefasste belebt, entwickelt, erweitert, verwan-

${ }^{33}$ Cfr. E. Cassirer, "Goethe und die...", p. 94. 
delt). Aunque Goethe utiliza las palabras «intuición" e «imaginación" en un sentido diferente al kantiano, puede pensarse que alude a la distinción entre imaginación productiva y reproductiva que puede leerse en las Vorlesungen über Anthropologie. La imaginación es productiva cuando genera nuevas imágenes, nuevos objetos que nunca antes habíamos aprehendido con nuestros sentidos o que nunca antes se habían presentado ante ellos; en tanto que creadora es el fundamento principal del genio, del que el espíritu imitativo está máximamente alejado. Es reproductiva cuando en ausencia del objeto renueva imágenes que ya antes se nos habían presentado; en este caso es sólo "copiadora": en su raíz se encuentra la imitación y la memoria. La imaginación productiva se subdivide a su vez en libre (cuando gracias a la actividad de su imaginación el ser humano puede suscitar y disolver imágenes a voluntad) y no-libre o "fantasía": «En la imaginación libre - escribe Kant- jugamos con las imágenes, en la fantasía las imágenes juegan con nosotros" (Bei der willkürlichen Imagination spielen wir mit den Bildern, bei der Phantasie spielen die Bilder mit uns). A diferencia de lo que sucede en la fantasía, la imaginación productiva supone una capacidad de síntesis (Vermögen der Synthesis): producir y disolver imágenes y ordenarlas de forma unitaria; a diferencia de la reproductiva (sometida a leyes empíricas y perteneciente al ámbito de la psicología), la imaginación productiva no es una capacidad meramente receptiva, pues implica espontaneidad en tanto que actividad transcendental en cuya raíz se encuentra una síntesis de la multiplicidad en una nueva unidad. Goethe, por su parte, entiende que la imaginación reproductiva (que él llama nachbildend, "copiadora») se limita a repetir objetos, mientras que la productiva queda caracterizada con los verbos «vivificar" "desarrollar" "ampliar» y "transformar". En el primer caso, estamos en el ámbito que denomina einfache Nachahmung, en el segundo en el del Styl, en el sentido del ensayo Einfache Nachabmung der Natur, Manier, Styl ${ }^{34}$ donde se ofrece una caracterización jerárquica y genética del arte, también "dialéctica» si se piensa que el «estilo» es síntesis entre la «imitación simple "y la «manera».

La imitación de la naturaleza puede ser "simple» (una mera reproducción) - "más elevada" si descansa "en los más profundos fundamentos del conocimiento o de la naturaleza": en tal caso se alcanza el "estilo" un concepto que tiene su origen en la antigua retórica pero que ya en el siglo XVII se utilizaba en el terreno artístico como contrapuesto al de maniera: depingere di maniera

${ }^{34}$ M.A. 3·2, 186 ss. 
era pintar caprichosamente a partir de la propia imaginación, no según y a partir de la naturaleza. Con palabras de Winckelmann: "El estilo antiguo estaba construido sobre un sistema que consistía en reglas que habían sido tomadas de la naturaleza y que a continuación se habían alejado de ella y se habían vuelto ideales. Se trabajaba más según la prescripción de estas reglas que según la naturaleza que había que imitar: pues el arte se había formado una naturaleza propia. Sobre este sistema aceptado se elevaban los cultivadores de las artes y se acercaban así a la verdad de la naturaleza" ${ }^{35}$.

Goethe se siente próximo a esta caracterización del "estilo" para él forma suprema de representación artística en tanto que configuración donde en la multiplicidad de los fenómenos se hace visible la legalidad que subyace a todos ellos y que en todos ellos se metamorfosea ${ }^{36}$. Die Metamorphose der Pflanzen lo expresa con rara intensidad poética; cito los últimos versos de esta elegía, en los que la metamorfosis se expresa como "ley eterna" que afecta al reino vegetal y al animal, pero también al ámbito de la educación y de las relaciones sociales, incluso al de la creación poética:

Dirige, oh amada, la mirada al multicolor hormiguero que movido ante el espíritu deja ya de desconcertarte.

Toda planta te anuncia, sí, la ley eterna, y toda flor habla alto y más alto contigo

Mas descifras aquí de la diosa la letra sagrada, por todas partes la ves, modificados sus rasgos.

Arrastrándose vacila la oruga, presurosa la mariposa, y el mismo hombre dúctil modifica la forma.

¡Oh! piensa como a partir de la semilla del trato poco a poco nos brota una dulce costumbre y la amistad con fuerza en nuestro interior se revela y como el amor, al fin, flores y frutos engendra.

Piensa que de mil maneras pronto esta o aquella forma desarrollándose en silencio a nuestro sentimiento da naturaleza. ¡Alégrate también del día de hoy! El amor sagrado se afana por el más alto fruto de una misma convicción,

${ }^{35}$ Geschichte der Kunst des Altertums, en Kleine Schriften, Vorreden, Entwürfe. Herausgegeben von W. Rehm, Berlin, Walter de Gruyter, 1968, p. 224.

${ }^{36}$ Cfr. R. Wild, Goethes klassische Lyrik, Stuttgart, Metzler, 1991, pp. 159-165. 
por la misma visión de las cosas, para que en armoniosa intuición se una la pareja y encuentre el mundo superior ${ }^{37}$.

Die Metamorphosen der Pflanze expresa y es expresión de la unidad entre ciencia y poesía y en esta medida entre arte y naturaleza, para la mirada morfológica de Goethe lo mismo y con idéntico poder creador. "Una obra de arte perfecta es una obra del espíritu humano y en este sentido también una obra de la naturaleza" escribe en Über Wahrheit und Warscheinlichkeit der Kunstwerke ${ }^{38}$. Tras su encuentro italiano con la Antigüedad y la flora mediterránea Goethe considera al arte "como una segunda naturaleza" ${ }^{39}$. En tanto que principio omniabarcador la naturaleza prescribe la legalidad que debe seguir el arte, pero tal legalidad toma forma en el discurso poético: la naturaleza sólo puede decirse poéticamente, como hizo, por ejemplo, Lucrecio. En Der Sammler und die Seinigen ${ }^{40}$ pueden leerse ulteriores precisiones sobre estas cuestiones.

En el trasfondo de esta especie de novelle epistolar se encuentra la controversia acerca del Laoconte entre Goethe y Aloys Hirt, el cual, en oposición a Winckelmann y Lessing, consideraba que el grupo escultórico expresa un dolor extremo, profundo; en la raíz de esta discrepancia se encuentra otra más pro-

37 Wende nun, o Geliebte, den Blick zum bunten Gewimmel,

Das verwirrend nicht mehr sich vor dem Geiste bewegt.

Jede Pflanze verkündet ,dir nun die ew'gen Gesetze, Jede Blume, sie spricht lauter und lauter mit dir.

Aber entzifferst du hier der Göttin heilige Lettern, Überall siehst du sie dann, auch in verändertem Zug.

Kriechend zaudre die Raupe, der Schmetterling eile geschäftig,

Bildsam ändre der Mensch selbst die bestimmte Gestalt!

$O$, gedenke denn auch, wie aus dem Keim der Bekanntschaft

Nach und nach in uns holde Gewohnheit entspross,

Freundschaft sich mit Macht in unserm Innern enthüllte,

Und wie Amor zuletzt Blüten und Früchte gezeugt.

Denke, wie mannigfach bald die, bald jene Gestalten,

Still entfaltend, Natur unsern Gefühlen geliehn!

Freue dich auch des heutigen Tags! Die heilige Liebe

Strebt zu der höchsten Frucht gleicher Gesinnungen auf,

Gleicher Ansicht der Dinge, damit in harmonischem Anschaung

Sich verbinde das Paar, finde die höhere Welt.

${ }^{38}$ M.A. 4.2, 94-95

${ }^{39}$ Italianische Reise, Rom, 11-August- 1787 (M.A. 15, 464).

${ }^{40}$ M.A. 6.2, 76 . 
funda que afecta a la comprensión del arte antiguo: Hirt piensa que no lo define ni la belleza ni la expresión mesurada, sino la expresión apasionada y "característica», la manifestación de situaciones y caracteres límites: "Laacon no grita porque ya no puede gritar. La lucha con lo horrendo y desmesurado (das Ungeheure) no comienza, ha finalizado" ${ }^{41}$. Pero ahora no interesa esta cuestión, sino el diálogo casi socrático entre el "característico" y el "filósofo" que se desarrolla a lo largo de las cartas 5 y 6 .

El "característico» defiende que no hay belleza sin caracteres, el "filósofo" (bajo el cual cabe reconocer sin mayores dificultades a Schiller) que el fin supremo del arte es la belleza y que su efecto último es el sentimiento de gracia (...das höchste Ziel der Kunst ist Schönheit und ibre letzte Wirkung Gefühl der Anmut). Imaginemos un hombre, argumenta el filósofo, que siente una peculiar inclinación por un objeto; si tiene además un impulso imitativo buscará representar de algún modo este objeto para luego, en un segundo momento, no darse por satisfecho con el objeto particular, pues en realidad no aspira al objeto, sino a su concepto. Responde entonces el "característico": en tal caso la obra de arte gustará precisamente por las "características" que pone de manifiesto. El filósofo da un paso más: «... gracias a aquella operación surgirá entonces un canon con valor modélico y apreciable teóricamente; pero insatisfactorio desde el punto de vista del ánimo». El "característico" considera que se está llegando "a muy oscuras regiones»; pero existe, de acuerdo con el filósofo, una luz que puede iluminarnos: la razón (Vernunft), pues el espíritu plantea exigencias al arte: no se satisface ni con la inclinación ni con la imitación ni con el deseo de saber: «... lo más elevado que hay en nosotros desea ser despertado, deseamos honrarlo y sentirnos a nosotros mismos como dignos de ser honrados». El característico: «Empiezo a no comprender absolutamente nada". El espíritu humano, continúa el filósofo, desea elevar un objeto y ser elevado por él, pero no es suficiente con ello, pues el ser humano también quiere regresar a sí mismo sin las limitaciones que experimentaba al comienzo, desea revivir la inclinación primigenia sin limitarla a un objeto particular: «¿Qué sería del ser humano en tal estado si la belleza no hiciera acto de presencia y solucionara felizmente el enigma!n. Pues las obras de arte recorren todo el círculo: comienzan siendo pura inclinación imitativa mas se elevan a lo

41 Aloys Hirt, "Laokon», en Die Horen, 3 (1797) 10 Stück; tb. "Nachtrag über Laokon", en Die Horen 3 (1797) 12 Stück. Pueden leerse estos textos en Goethe. Über Laokon. Dokumente zu Vorgeschichte und Wirkung (Bibliothek der Kunstliteratur 3, pp. 622-623). 
universal para ser de nuevo una especie de individuo que cabe abarcar con nuestra inclinación y apropiárnoslo. Queda así caracterizado, con palabras schillerianas, el tránsito de la "imitación simple de naturaleza» al "estilo" en sentido estricto y auténtico. Pero por detrás de todo ello hay un problema verdaderamente grave: la kantiana presuposición epistemológica que está en la raíz del planteamiento del «filósofo»: que toda experiencia es producida (Es gibt keine Erfahrung die nicht produziert, hervorgebracht, erschaffen wird). Comenta entonces el "característico»: "Esto sí que es demasiado». Sin embargo, replica el filósofo, se trata de algo que vale particularmente para el artista (Besonders gilt es von dem Künstler).

Schiller es un filósofo y un artista: la problemática epistemológica y la estética se iluminan recíprocamente y lo hacen en términos kantianos. En la Crítica del discernimiento había escrito Kant: "Pues a pesar de toda la uniformidad de las cosas naturales conforme a leyes, sin las cuales no tendría lugar la forma de un conocimiento empírico en general, cabe muy bien pensar que la diferencia específica de las leyes de la naturaleza junto a sus efectos podría ser tan grande que fuera imposible para nuestro entendimiento descubrir en ella un orden inteligible, al dividir sus productos en géneros y especies, para emplear los principios de la explicación y comprensión del uno también como explicación y conceptualización del otro, $y$ hacer así a partir de una materia tan confusa para nosotros (bien mirado, sólo infinitamente diversa e inadecuada para con nuestra inteligencia) una experiencia coherenten ${ }^{42}$. Porque de acuerdo con el planteamiento kantiano no se trata de la organización de la naturaleza conforme a sus leyes universales, sino de progresar en la experiencia y adquirir conocimiento con el uso de nuestro entendimiento y en la medida de nuestras capacidades. El "realista" Goethe no respetó esta limitación: para él "la organización de la naturaleza» se solapa exactamente con su conocimiento, de suerte que el tránsito de la consideración de la naturaleza a la consideración artística se da sin solución de continuidad, porque —escribe en la [183] de sus Maximen und Reflexionen - lo bello "es una manifestación de leyes secretas de la naturaleza, sin cuya presencia esas leyes habrían permanecido eternamente ocultas para nosotros».

No es, pues, que la problemática epistemológica se convierta en estética, como en ocasiones parece sugerir Schiller, sino que aquélla se reformula en términos de ésta por la sencilla razón de que la misma naturaleza ofrece el modelo, pero éste, a

${ }^{42}$ B XXXVII-XXXVIII. 
su vez, coincide con lo que Goethe mismo experimenta en su subjetividad como artista, que intuición e imaginación van de la mano. En manos de Goethe la investigación transcendental sobre de las condiciones de posibilidad del conocimiento se convierte en intento de explicar los mecanismos en virtud de los cuales el artista crea su obra, los mecanismos en virtud de los cuales el artista crea su obra de arte se extienden a la naturaleza como un Todo y la naturaleza como un Todo explica los mecanismos en virtud de los cuales el artista crea su obra, porque, en el fondo, como ya dijo Schaftesbury, "All Beauty is Truth": eso es todo ${ }^{43}$.

Se comprende ahora que Goethe entendiera que Kant, en la Critica del discernimiento, había tratado los productos de la naturaleza y los del arte de la misma manera: "El discernimiento estético y el teleológico se iluminan recíprocamente ${ }^{44}$. Tampoco sorprende que señalara que se había procedido de esta manera para alcanzar cierta armonía entre las exigencias abstractas de la razón analítica y las de la intuición sensible inmediata. Goethe sabe con Kant que el entendimiento humano no puede satisfacerse con la recolección y clasificación de fenómenos particulares (como hizo, por ejemplo, Linné en el campo de la botánica), pues busca además señalar sus interrelaciones, las condiciones bajo las cuales cambian sus apariencias, la legalidad a la que obedecen. Sin embargo, en virtud del hermanamiento entre intuición e imaginación, piensa que los elementos de la síntesis final son los mismos que aparecen en la intuición empírica inmediata, a diferencia de Kant y en general de toda teoría del conocimiento que no olvida que en la física newtoniana tales elementos deben antes transformarse en valores cuantitativos susceptibles de ser expresados matemáticamente ${ }^{45}$.

Schiller nunca cejó de intentar convertir a Goethe al kantismo, con celo misionero digno mejor causa; pero el "gran pagano» llegaba hasta donde llegaba o hasta donde le interesaba llegar: "... todo depende de la elucidación de la cuestión que tanto ocupa a los filósofos, a saber, en qué medida un objeto que nos es dado por la experiencia podemos verlo como un objeto en sí o tenemos que

43 Cfr. J. Kears, "Ode on a grecian urn» (vv. 49-50):

Beauty is truth, truth beaty, -that is all

Ye know on earth, and all ye need to know.

44 "Einwirkung der neueren Philosophie" (M.A. 12, 96).

45 Cfr. E. Cassirer, "Goethe und die mathematische Physik. Eine erkenntnistheoretische Betrachtung", en Idee und Gestalt. Goethe-Schiller-Hölderlin-Kleist, Darmstadt, Wissenschaftliche Buchgesellschaft, 1971. 
verlo como nuestra obra y nuestra propiedad (...als ein Gegenstand an sich ansehen dürfen oder ihn als unser Werk und Eigentum ansehen müssen). Pues si se afronta al asunto con atención se ve entonces que no sólo los objetos del arte (Gegenstände der Kunst), sino los objetos para el arte (Gegenstände zur Kunst) poseen en sí una cierta idealidad; pues en tanto que son considerados por referencia al arte, quedan ya de suyo modificados por el espíritu humano. Si no me equivoco el idealismo crítico afirma algo parecido acerca de toda empiria y todo depende de si en nuestro caso, en el que ciertamente no suponemos una creación (Erschaffung) de los objetos, pero sí una metamorfosis, podemos expresar tan claramente el hecho de que podamos ser comprendidos universalmente y de que podamos caracterizar de manera pertinente la diferencia entre el objeto y la manera de tratarlo (zwischen Gegenstand und Behandlung) "

De acuerdo con este texto parece que se admite cierta «idealidad»: la Roma de las Elegías, por ejemplo, no es la ciudad real y empírica, sino Roma objeto para el arte. Pero esta idealidad no es "en sín sino sólo por la "manera de tratar" al objeto. Goethe acepta que la intuición sensible, en este caso del artista, transforma su objeto, que de estado de cosas empírico pasa a ser objeto artístico, pero entonces, con olímpico desprecio por toda teoría del conocimiento más o menos kantianizante, rehuye el siguiente paso: no disocia percepción e intuición, pues entiende la segunda como intensificación y acrecentamiento (Steigerung) de la primera. La teoría del conocimiento sostiene que toda percepción destruye y disgrega la facticidad del objeto percibido por mor del aparato categorial o, en otras versiones, de los específicos conocimientos previos e intereses del sujeto que percibe. Goethe se limita a lamentar la miopía de tal sujeto, pues él, que posee una mirada morfológica y metamorfoseante, puede ver el objeto enteramente y en su facticidad: su intellectus es archetypus, por decirlo con una expresión kantiana sobre la que habrá que volver más adelante.

\section{IV}

Goethe quedó sorprendido porque los pintores que frecuentó en Italia rentalizaban en beneficio de su labor artística sus conocimientos cientificos en el ámbito de la perspectiva o la anatomía, mientras que en el del color procedían

${ }^{46}$ A Schiller, 25-Octubre-1795. 
de manera totalmente arbitraria ${ }^{47}$. La preocupación caía sobre suelo abonado, pues el poeta ya se había sentido atraído por el sentido místico y alquímico de los colores cuando en su juventud se sintió próximo al círculo de Suzanne von Klettenburg, el «alma bella» del libro VI de los Wilhelm Meister Lehrjahren ${ }^{48}$. Cuando regresó de Roma, tal vez por llenar el vacío que sentía, comenzó a interesarse por los fenómenos ópticos. Goethe creía que, de acuerdo con Newton, al atravesar un rayo de luz blanca un prisma la luz tendría que descomponerse en colores. Hizo entonces el "experimento»: cogió un prisma, miró a través de él y para su sorpresa encontró que los colores sólo aparecían en los márgenes, en la zona de transición entre luz y oscuridad. Concluyó entonces que la hipótesis newtoniana era falsa e insostenible ${ }^{49}$. En sentido estricto, Newton no había afirmado que los colores estaban contenidos en la luz blanca, sino que en lo que percibimos como luz blanca (la luz del sol) hay ciertas realidades físicas (rayos con diferentes grados de refracción) que tienen la capacidad de provocar en nosotros la sensación de colores diferentes. Es muy probable que si Newton, en vez de hablar de "rayos de luz» lo hubiera hecho en términos de "longitudes de onda" la actitud de Goethe no habría sido tan agria, pues los rayos se ven, mientras que las longitudes de onda son constructos matemáticos. Newton tenía en la mente un fenómeno cuantitativo o la cuantificación de un fenómeno, pero no tuvo más remedio que expresarlo con terminología cualitativa. En cualquier caso, Goethe quedó horrorizado y apoyándose en Athanasius Kircher, que había descrito el color como lumen opacatum, lo define sirviéndose de la palabra griega skieron: el color es una especie de «sombra» resultante de la interacción y polaridad entre luz y oscuridad. Es cierto que la mezcla de una y otra no da colores, sino manchas grises, pero Goethe sostenía que en un medio túrbido (trübes Medium) como el vapor, las nubes, el humo, el agua o el cristal tal combinación sí daba como resultado el color en virtud de un proceso de intensificación (Steigerung).

${ }^{47} \mathrm{Cfr}$ la "Konfession des Verfassers" que Goethe incluye en la parte histórica de su Farbenlehre (M.A. 10, 902 ss). Tb. Geschichte der Arbeiten des Verfassers in diesem Fache (M.A. 6.2, 798 ss).

${ }^{48} \mathrm{Cfr}$. S. Mas, "El mito de una subjetividad bella", en Johann W. Goethe. Confesiones de un alma bella, Madrid, Mínimo Tránsito/Antonio Machado, 2001. Sobre los intereses y las inquietudes alquímicas de Goethe veáse R.D. Gray, Goethe the Alchemist. A Study of Alchemical Symbolism in Goethe's Literary and Scientific Work, Cambridge Univ. Press, 1952.

${ }^{49}$ Sobre estas cuestiones cfr. D.L. Sepper, Goethe contra Newton. Polemics and the Project for a New Science of Color, Cambridge Univ. Press, 1988, p. 27 y ss. Tb. F. Burwick, The Dammation of Newton. Goethe's Color Theory and Romantic Perception, Berlin, Walter de Gruyter, 1986, y A. Schöne, Goethes Farbentheologie, München, Beck, 1987. 
No interesan ahora los pormenores de la argumentación goetheana, sólo señalar que al igual que los restantes fenómenos de la naturaleza el color en tanto que impresión sensible inmediata obedece a las leyes de la "polaridad" y la "intensificación " y que tales leyes no son constructos teóricos que permiten la aprehensión de los fenómenos (en sentido kantiano) cromáticos, sino realidades en sí que Goethe ve con la misma intensidad y claridad (utilizando los "sanos sentidos") con la que ve, pongamos por caso, que esta flor es amarilla y aquella roja. Pues Goethe sostiene que sus Urphänome son tanto reales como ideales, inteligibles y a la vez sensibles, y defiende además que los órganos de los sentidos son análogos a los fenómenos que perciben; la luz y el ojo son entidades complementarias: «... el ojo debe su existencia a la luz" escribe en la "Introducción" a su Farbenlehre, apuntando así a la absoluta identidad entre sujeto y objeto: por ello puede el primero decir al segundo en su más absoluta inmediatez, ahora bien, sólo si usa sus «sanos sentidos" y no se extravía en "alegorías» matematizantes o mitificantes. En el "Prefacio» a la parte didáctica de la Farbenlehre puede leerse que los colores son acciones y pasiones de la luz (Die Farben sind Thaten des Lichts, Thaten und Leiden). Schopenhauer lo interpretó en el sentido de que los colores son acciones y pasiones de la retina ${ }^{50}$; cierto pero no sólo, señala Goethe, también lo son de la luz. Schopenhauer ofrece así otro ejemplo de alejamiento de la naturaleza en su discurrir espontáneo y natural, pues al argumentar de este modo pone de manifiesto que no le interesan realmente los colores que se ven, sino que su investigación obedece más bien a un interés por la fisiología de la percepción en función, a su vez, de una nueva demostración, apoyada en argumentos fisiológicos, de la naturaleza a priori de la causalidad ${ }^{51}$.

Hay ocasiones en las que Goethe, tal vez dejándose llevar por el espíritu de una época en la que no ser "idealista" en alguna de sus versiones era una excentricidad, parece aceptar los planteamientos kantianos de la "Segunda Introducción" a la Crítica de la razón pura; en carta a Schiller del 6 de Enero de 1798, por ejemplo, escribe: «Acepto con gusto que no conocemos la naturaleza, sino que nosotros sólo la aprehendemos según ciertas formas y capacidades de

${ }^{50}$ Cfr. Uber das Sehn und die Farben, en Sämtliche Werke, Bd. III. Textkritisch bearbeitet und herausgegeben von Wolfgang Frhr. von Löhneysen, Darmstadt, Wissenschaftliche Buchgesellschaft, 1962, pp. 193 y ss.

si Cfr.P.F.H. Lauxtermann, Schopenhauer's Broken World-View. Colours and Ethics between Kant and Goethe, Dordrecht, Kluwer, 2000, pp. 74 y ss. 
nuestro espíritu (...sondern daß sie nur nach gewissen Formen und Fähigkeiten unsers Geistes von uns aufgenommen wird)". Sin embargo, su "tic realista" " demasiado poderoso: entre el apetito que siente un niño por una manzana y la manzana que sugirió a Newton su teoría hay, escribe, "muchos niveles del intuir" (sehr viele Stufen des Anschauen) y querría saber cuál de ellos es el más elevado (...was man für die höchste hält). Sigue entonces con una alusión a la filosofía de la naturaleza de Schelling, para el cual, como es sabido, todos los productos orgánicos son autónomos en sí mismos y portan el fundamento de su existencia en sí mismos como espíritu inconsciente que sólo en el hombre despierta a su propia autoconciencia: lo que para Kant era un principio teleológico regulativo desde el punto de vista metodológico en Schelling se convierte en principio constructivo de la naturaleza. Goethe insiste: tanto da que el idealista acepte o rechace la cosa en sí, lo único cierto es que acaba chocando con la cosa fuera de sí. Schiller, muy prudentemente, no comenta esta carta de Goethe, tal vez porque aún recordara la del 15 de Noviembre de 1796: "Las investigaciones sobre la naturaleza me alegran mucho. Parece extraño y es, sin embargo, natural que finalmente tenga que surgir una especie de todo subjetivo. El mundo del ojo se consuma en figura y color. Pues si pongo atención sólo parcamente necesito la ayuda de los otros sentidos y todo razonamiento se transforma en una especie de exposición (...und alles Raisonnement verwandelt sich in einer Art von Darstellung)" ${ }^{53}$.

No deja de ser significativo que Goethe, en su siguiente carta (10-enero1798), después de comentar que vuelve a ocuparse de la teoría de los colores, le haga llegar el ensayo Der Versuch als Vermittler von Objekt und Subjekt, donde insiste en la necesidad de superar la subjetividad del observador científico en una objetividad controlable de forma metódica que asegure la intersubjetividad de los enunciados científicos. A tal fin el experimento tiene una importancia decisiva, pero en contra de Newton y del proceder de la ciencia moderna rechaza la relevancia metodológica del experimentum crucis, niega que un experimento único pueda decidir la corrección o falsedad de los enunciados científicos, pues «en la naturaleza viviente no acontece nada que no esté en relación con el Todo, y si las experiencias se nos aparecen aisladas cuando consideramos los experimentos como hechos aislados, ello en modo alguno quiere decir que las expe-

\footnotetext{
${ }^{52}$ A Schiller, 9-Julio-1796; cfr. tb. la respuesta de Schiller del 9/11-Julio-1796.

${ }^{53}$ Cfr. Betrachtung über Morphologie überhaupt (M.A. 4.2, 200); tb. Das Auge (M.A. 6.2,
} 814). 
riencias sean aisladas...." ${ }^{54}$. La imbricación cósmica de todos los fenómenos de la naturaleza exige la ligazón metodológica de los experimentos: frente a la repetición de un experimento único Goethe propone la «multiplicación de cada experimento particular» bajo la forma de una serie de experimentos de tipo similar en los que el fenómeno investigado se percibe de varias maneras, en cada una de ellas desde perspectivas ligeramente modificadas, pues sólo así, no desde un experimento único sino desde variaciones experimentales (en el sentido musical de la palabra «variación»), se conservan y respetan las múltiples relaciones que el fenómeno investigado guarda con el todo de la naturaleza y no se pierde lo que Goethe en modo alguno quiere perder, aquello cuya ignorancia es condición de posibilidad de la ciencia moderna, la consideración de la naturaleza como totalidad fácticamente dada. Brevemente, la ciencia debe proceder como lo hace la misma naturaleza: morfológicamente. Con razón entiende Schiller que el citado ensayo contiene una justificación del proceder científico de Goethe.

Goethe era un hombre por lo general conciliador y por eso llama poderosamente la atención la virulencia de sus críticas a Newton. "El ser humano sólo se conoce a sí mismo —escribe en Bedeutendes Fördernis... - en la medida en que conoce al mundo que sólo percibe en sí, y a sí mismo sólo se percibe en él. Cualquier objeto nuevo, contemplado adecuadamente, pone de manifiesto un nuevo órgano en nosotros». El órgano y su objeto, el ser humano y el mundo, se implican y exigen mutuamente; de aquí que haya que escuchar a la naturaleza, porque ésta "habla": "Así habla la naturaleza descendiendo hacia los otros sentidos, hacia sentidos conocidos, desconocidos o ignorados, así habla ella consigo misma y a nosotros por medio de miles de fenómenos" ${ }^{55}$. Prestar atención a este lenguaje y escuchar su mensaje: tal es la tarea de la ciencia. No hace falta insistir una vez más en lo alejado que este planteamiento se encuentra de la ciencia newtoniana y de la epistemología kantiana. Pero el asunto no es o no es sólo científico-técnico, va más allá, pues al reducirse voluntariamente a un ámbito estrechísimo de fenómenos, aquellos susceptibles de expresión matemática, la ciencia moderna ha dejado el campo libre a la irracionalidad y al desbocado subjetivismo de los románticos ${ }^{56}$. El terreno despreciado por la ciencia moderna ha

${ }^{54}$ Der Versuch als Vermittler von Objekt und Subjekt (M.A. 4.2, 328 y s). Cfr. tb. la correspondencia entre Goethe y Schiller: 10 al 13 de Enero de 1798.

${ }^{55}$ Zur Farbenlehre "Vorwort" (M.A. 10, 9)

${ }^{56}$ Cfr. H.J. Schrimpf, "Über die geschichtliche Bedeutung von Goethes-Newton Polemik und Romantik-Kritikn, en Der Schriftsteller als öffentliche Person. Von Lessing bis Hochmuth, Berlin, Schmidt, 1977, pp. 127 y ss. 
sido ocupado de inmediato por los «klosterbrudiserende, sternbaldischen Unwesen " y por los "kränklichen Klosterbruder und seine Genossen" dice Goethe jugando y parodiando las Franz Sternbalds Wanderungen de Tieck y las Herzenergiessungen eines kunstliebenden Klosterbruder de Wackenroder.

Hay que dejar atrás "la física" (y por tal Goethe entiende el magnetismo, la electricidad y el "quimismo») ${ }^{57}$ y elevarse a esas regiones más elevadas donde la ciencia y el arte se encuentran, unidad imposible si la ciencia es la de Newton, el arte el de lo románticos y la epistemología la kantiana, pero posible para la mirada morfológica de Goethe, que por encima o más allá de las limitaciones señaladas por Kant, es capaz de percibir la unidad y diversidad de los fenómenos físicos, zoológicos o botánicos.

\section{$\mathrm{V}$}

Schiller, ya lo he recordado, señalaba que la metamorfosis no es una "experiencia" sino una "idea" ${ }^{58}$; tal vez quería decir que con ella no se expresa la realidad de la cosa «en sí» sino una expectativa teórica o un principio regulativo en tanto que intuición estructuradora: lo empíricamente percibido (lo que Goethe llama "experiencia») es lo teórico, la idea. Goethe, por su parte, que se niega radicalmente a elaborar una teoría del conocimiento, entiende las kantianizantes tesis schillerianas en el sentido de que no puede haber una experiencia adecuada a las ideas en tanto que universales que toman cuerpo en los objetos de conocimiento $^{59}$. Es cierto que posteriormente Goethe entendió sus Urphänome como «símbolos", con lo cual no se gana gran cosa, pues no es fácil determinar con precisión la distancia que separa lo simbólico de lo alegórico ${ }^{60}$.

${ }^{57}$ Cfr. M. WENZEL, «Die Abstraktion, von der wir uns fürchten... Goethe und die Physik», en en G. Schnitzler, G. Schramm, (Hrsg.), Ein unteilbares Ganzes. Goethe: Kunst und Wissenschaft, Freiburg, Rombach, 1997.

58 "Glücklicher Ereignis" (M.A 12, 88 y ss).

${ }^{59}$ Cfr. A. Schmidr, Goethes herrlich leuchtende Natur. Philosophische Studien zur deutschen Spätaufklärung, München, Hanser, 1984, p. 36.

${ }^{60}$ Cfr. B.A. Sörensen, Symbol und Symbolismus in der ästhetischen Theorie des 18. Jahrhunderts und der deutschen Romantik, Kopenhagen: Munksgaard, 1963. Del mismo autor: Allegorie und Symbol. Texte zur Theorie des dichterischen Bildes im 18. und frühen Jahrhundert. Ausgewahlt, kommentiert und mit einem Nachwort versehen von..., Frankfurt am Mein: Athenäum, 1972. Tb.: "Zum Problem des Symbols und der Allegorie bei Goethen, en Goethe Jahrbuch, 94, 1977. 1963 y 1972. 
La definición que ofrece Goethe en Über die Gegenstände der bildende Kunst es en principio sencilla y toma pie en la distinción entre dos formas o dos estrategias de designación, directa e indirecta: "Lo alegórico se diferencia de lo simbólico en que éste designa directa aquél indirectamente ${ }^{61}$. El asunto se complica porque a esta escueta diferenciación se sobrepone una tripartición: en el arte caben tres formas de proceder, "natural» «ideal» $\mathrm{y}$ «una tercera»; junta a ellas o quizá mejor más allá de ellas hay aún una cuarta, en los mismos límites de lo simbólico y, por así decirlo, rozando lo místico. En toda representación simbólica los objetos se determinan por su mismo ser sensible, de suerte que aparezcan tal y como son, si bien -advierte Goethe- elevados "a un todo artístico" ( $z u$ einem Kunstganzen erhöht); de ella se exige que se explique a sí misma al margen de toda mediación subjetiva, nada más verla (beim ersten Anschauen). En la tercera forma de representación simbólica los objetos representados se hacen comprensibles cuando se explican por las consecuencias de la acción; por ejemplo, Hércules por sus hazañas. La cuarta forma de representación abandona el territorio de lo simbólico porque en ella se prescinde de toda referencia objetual y se entra en el terreno de lo extremadamente subjetivo; el objeto de representación no se elucida por el objeto representado, sino por el sujeto que representa. Se rompe así esa "comunicación" de la que habla Goethe en carta a Schiller del 15 de Septiembre de 1797: «... esta materia comunica con lo más íntimo del arte».

Goethe presupone que hay un "profundo sentimiento" (tiefe Gefuible) que cuando es "puro y natural" coincide con los objetos más elevados y más excelentes y los representa de manera simbólica. Pero este sentimiento puede extraviarse y entonces las estrategias de representación parecen estar por sí mismas y ser significativas en lo más profundo "debido — añade - a lo ideal, que siempre lleva consigo una universalidad». Parece que Goethe, al modo de Friedrich Schlegel o de Schelling, invita a pensar lo máximamente subjetivo como lo máximamente universal; sin embargo, ese "profundo sentimiento" que se ha extraviado está próximo al Schwärmerei ("fanatismo" "exaltación" "extravagancia"...) de la Crítica del discernimiento: «...que es una ilusión de querer ver algo por encima de todos los límites de la sensibilidad, esto es, soñar según principios (deliberar con la razón) (...) En el entusiasmo, en tanto que afecto, la imaginación está desbocada; en la exaltación, en tanto que pasión arraigada, carece de

${ }^{61}$ Cfr. Über die Gegenstände der bildende Kunst (M.A 4.2, 121-124). 
reglas. El primero es un accidente pasajero que en ocasiones afecta al entendimiento más sano, el segundo una enfermedad que lo arruina" ${ }^{62}$.

Con ocasión de una recensión de los relatos de E.T.A. Hoffman recogidos en las Fantasiestücke in Callots Manier Goethe habla de "maldad" "enfermedad" $y$ "profunda locura" ${ }^{63}$; en 1827 lee en la Foreign Quaterly Review (1-Julio-1827) el ensayo de Scott sobre Hoffmann "On the Supernatural in Fictitions Compositions" y hace suya la opinión del escritor inglés: "sueños delirantes de un cerebro enfermo" "la enfermiza obra de un hombre que sufre" "uso inmoderado del opio" ${ }^{64}$; la exigencia hoffmaniana de que el artista debía esforzarse por "....aprehender con todas sus formas, colores, luces y sombras la imagen que le ha nacido en su interior, y cuando se siente verdaderamente empapado de ella llevar la representación a la vida externa ${ }^{65}$ la consideraba un sinsentido "que carece de forma y de límites" una ensoñación nocturna vacía y fantasmal. Las Herzenergiessungen eines kunstliebenden Klosterbruders están en el origen del "arte neo-alemán patriotico-religioso" y su autor, Wackenroder, es un "joven enfermo"; de acuerdo con las Herzenergiessungen..., señala Goethe, el arte ni se enseña ni se aprende, está sin embargo en una relación tan íntima con la religión que se exige del artista "éxtasis de piedad y sentimientos religiosos como si fueran condiciones indispensables de la capacidad artística» ${ }^{66}$.

Cuando Goethe habla de "un profundo sentimiento no extraviado" no se refiere ni al delirio ni a la religión, al contrario, piensa más bien en la necesidad de decir la naturaleza en su pura inmediatez, pues aunque el arte, al igual que la ciencia, es una forma de representación en la que algo dice algo otro, en la que intervienen dos polos, el decir y lo dicho, ni el arte ni la ciencia "imitan" a la naturaleza, tampoco le hacen decir algún sentido, ajeno a ella, místico, religioso o moral, sino que simplemente la expresan: el arte y la ciencia son dos estrategias simbólicas de decir la naturaleza; se entiende así que aunque los objetos representados de modo simbólico "parezcan estar por sí mismos" sean sin embargo significativos "en lo más profundo".

62 B 125.

${ }^{63}$ A C.A. Eichstädt, 10-Marzo-1815. Goethe nunca llegó a escribir esta recensión.

${ }^{64}$ Schriften zur Literatur (M.A. 18.2, 94-97); Tb. Maximen und Reflexionen [1031] (M.A. $17,893)$

"Se trata del "principio de Serapión" (serapionische Prinzip) que está en la raíz de la poética de Hoffmann. Cfr. Die Serapionsbruder, en Sämtliche Werke, Bd. 4, hrsg. von W. Segebrecht und U, Segebrecht, Frankfurt a M, Deutscher Klassiker Verlag, 2001, p. 69.

${ }^{66}$ Neu-deutsche religios-patriotische Kunst (M.A. 11.2, 319). 
Tal vez Goethe tenga en la mente esa restitución de la sensorialidad que Hamann había pedido en su Aesthetica in Nuce; la realidad, señala, se aprehende bildlich: «En las imágenes (in Bildern) está todo el tesoro del conocimiento y la felicidad humanas. La primera irrupción de la creación y la primera impresión de su historiador, la primera aparición y el primer disfrute (Genuss) de la naturaleza se unifican en las palabras: ique se haga la luz! ${ }^{67}$. No hay que olvidar, sin embargo, que los románticos comparten una idea fundamental de Hamann: que los objetos de la naturaleza hablan o han hablado en el pasado y que los seres humanos, al menos algunos de ellos, los artistas, pueden comprender la naturaleza como lenguaje. La historia de la naturaleza sería así la de la pérdida de comprensibilidad de su lenguaje, un proceso que de acuerdo con Hamann culmina con el racionalismo ilustrado y con Newton. De aquí que el arte no pueda ser imitación de la naturaleza: por la sencilla razón de la que la naturaleza ya no está o ha quedado muda. Pero en otro sentido, más profundo y decisivo, el principio de la imitación sigue vigente como mímesis de la naturaleza en su fuerza originaria creadora $^{68}$. Tal vez muy a su pesar, Goethe está peligrosamente cerca de los románticos; de aquí quizá su insistencia en afirmar que lo simbólico no pierde el punto de referencia en "lo visible" y este deseo de ver y decir las cosas en su pura materialidad, superada la fase wertheriana, es una constante en toda su obra ${ }^{69}$. Por eso Goethe afirma esa absoluta preeminencia de la intuición sensible (Anschauung) que se expresa, por ejemplo, en una carta del 3 de Diciembre de 1795 dirigida a Wilhelm von Humboldt donde confiesa que en sus trabajos científicos todo depende de una concepción no subjetivista de la intuición, por la cual entiende una especie de ósmosis entre el sujeto y el objeto o un sumergirse del pensamiento en el objeto ${ }^{70}$. La metamorfosis, decía Schiller, es una idea: Goethe, por su parte, se alegra de tener ideas sin saberlo y de poder verlas con los ojos.

La sombra de Kant es alargada, pues en el trasfondo de todas estas cuestiones se encuentra la posibilidad, imaginada en la Critica del discernimiento, de un entendimiento que a diferencia del nuestro (intellectus ectypus) no fuera discursi-

${ }^{67}$ Aesthetica in Nuce, en Schriften zur Sprache, Frankfurt a.M., 1967, p. 114. Cfr. F. Apel, en S. Schulze 1994.

${ }^{68}$ Cfr. "Die romantische Schule des Sehens", en Romantische Kunstlehre. Bibliothek der Kunstliteratur 4. Hrsg. von F. Apel, Frankfurt a.M., Deutscher Klassiker Verlag, 1992, pp. 722 y ss.

${ }^{69}$ Cfr. F. Apel, «Der lebendige Blick. Goethes Kunstanschauung», en S. Schulze, op. cit.

${ }^{70}$ Cfr. G. Benn, "Goethe und die Naturwissenschaften", en H. Mauer (Hrsg.), Goethe im XX Jahrbundert. Spiegelungen und Deutungen, Hamburg, Wegner, 1967, p. 409. 
vo, sino intuitivo (intellectus archetypus). El parágrafo 77 de esta obra ( $\mathrm{De}$ la peculiaridad del entendimiento humano en virtud de la cual se torna posible para nosotros el concepto de un fin natural") señala que en el proceso de conocimiento nuestro entendimiento tiene que ir de lo analítico-universal a lo particular, esto es, desde los conceptos a la intuición dada empíricamente; sin embargo, "nosotros también podemos pensar un entendimiento que no sea discursivo, como el nuestro, sino intuitivo y que vaya de lo sintético-universal (de la intuición de un todo en cuanto tal) a lo particular». Kant señala que "si no queremos representarnos la posibilidad del todo como dependiente de las partes (...) sino que queremos representarnos la posibilidad de las partes según su índole y enlace» esto no puede ocurrir "con arreglo a la peculiaridad de nuestro entendimiento" sino "según la medida del entendimiento intuitivo (arquetípico)». Nótese que no se afirma ni la posibilidad ni mucho menos la existencia de tal intellectus archetypus, «sino sólo que, al confrontarlo con nuestro entendimiento discursivo, menesteroso de imágenes (intellectus ectypus), y ante la contingencia de semejante dotación, somos llevados a esa idea, que tampoco entraña contradicción alguna».

Goethe en modo alguno guardó estas precauciones kantianas: pensó que el talento artístico presupone y a la vez pone de manifiesto ese intellectus archetypus que Kant, en todo caso, habría reservado a la divinidad y que Goethe siente que posee en tanto que poeta, es decir, en tanto que como poeta investiga la naturaleza. No cabe otra posibilidad, a menos que se desee pagar, como en efecto se ha hecho, el alto peaje que implica el desarrollo de la ciencia y de la técnica newtoniana. A despecho de sus furibundos ataques a los románticos no puede sorprender que Novalis considerara a Goethe "el primer físico de su época»" ${ }^{71}$.

${ }^{71}$ "[Über Goethe]». Vorarbeiten 1798, en Das philosophisch-theoretische Werk. Herausgegeben von Hans-Joachim Mähl, München Hanser, pp. 412-414. 